
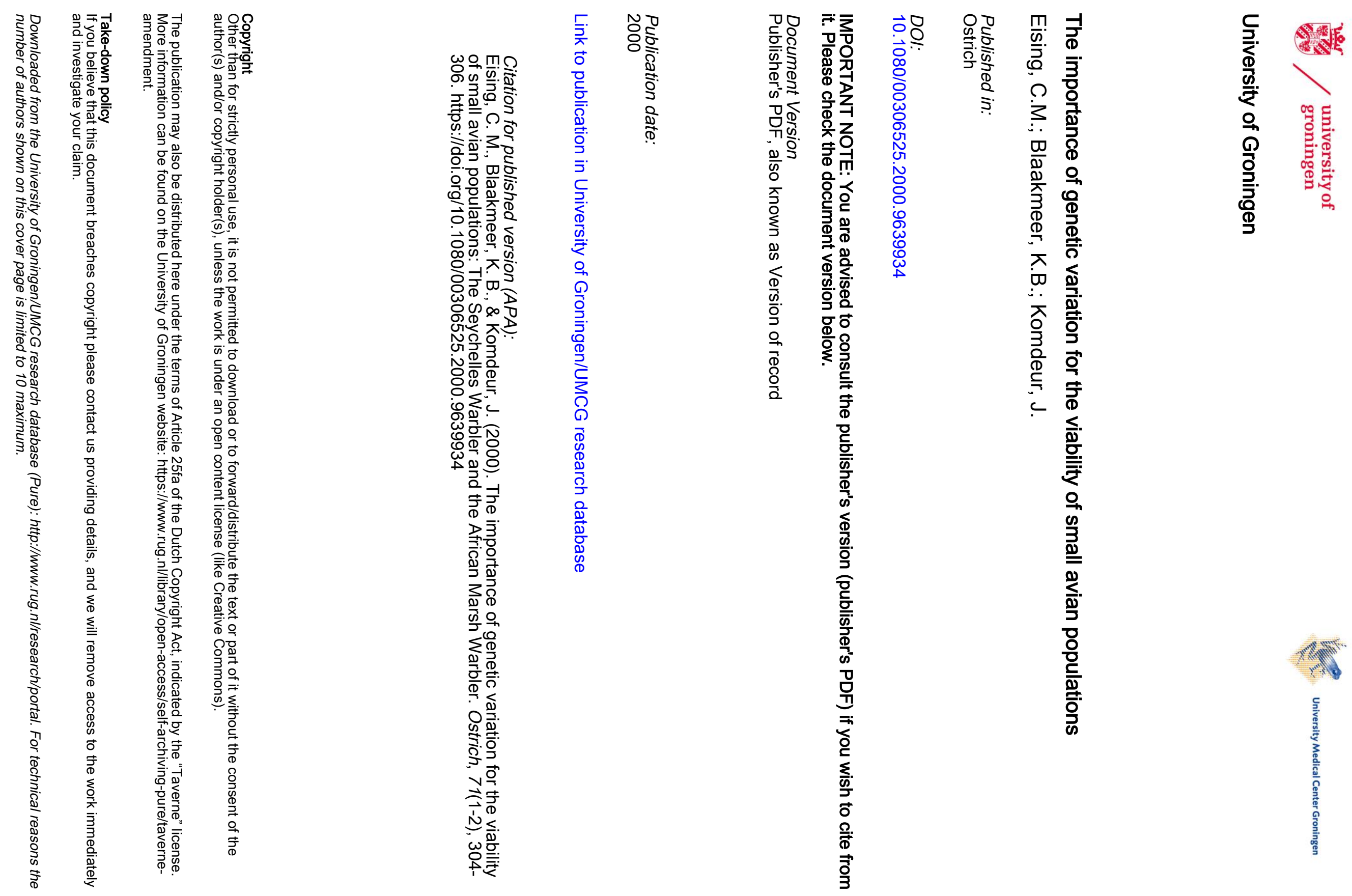


\title{
The importance of genetic variation for the viability of small avian populations - the Seychelles Warbler and the African Marsh Warbler
}

\author{
C.M. Eising ${ }^{1}$, K.B. Blaakmeerl, 2 \& J. Komdeurl, 3 \\ 'Zoological Laboratory, University of Groningen, P.O. Box 14, 9750 AA, Haren, The Netherlands. \\ 'Department of Genetics, University of Groningen, The Netherlands. \\ ${ }^{3}$ Department of Zoology, University of Melbourne, Parkville, Victoria 3052, Australia.
}

\begin{abstract}
Eising, C.M., Blaakmeer, K.B. \& Komdeur, J. 2000. The importance of genetic variation for the viability of small avian populations - the Seychelles Warbler and the African Marsh Warbler. Ostrich 71 (1 \& 2): 304-306.

Nowadays, many natural populations have to face up to problems such as genetic drift and 'forced' inbreeding as a result of reduced numbers and population isolation. This is thought to have a major effect on their survival. Research on the isolated Seychelles warbler showed that fitness parameters are not negatively affected by a high inbreeding frequency and a low level of heterozygosity. However, one has to be careful to translate these results to other isolated species. It is hypothesised that the effect of 'genetic erosion' on fitness may be less disastrous for island species, which are used to go through narrow population bottlenecks, as compared to continental species. Conservationists should be aware of these differences between species and of the fact that the long-term prospects can be reduced by lack of adaptive genetic potential.
\end{abstract}

\section{INTRODUCTION}

A key concept in conservation biology is that populations are subjected to certain demographic thresholds, below which nonadaptive, random forces can prevail over evolutionary adaptive forces. Especially in small populations genetic drift can outweigh natural selection, causing alleles to become fixed in a random fashion (Soulé 1987; Komdeur \& Deerenberg 1996). In addition, environmental stochasticity, that is the occurrence of events that are not predictable, would lead to enhanced fluctuations in population numbers and thus enhanced risk of extinction.

Nowadays, many natural populations are becoming smaller and more isolated because of habitat fragmentation and non-sustainable use, leaving them vulnerable to such factors as genetic drift. This may have serious consequences for the survival of these small populations, since in small populations there can also be a tendency for inbreeding, which is the incidence of matings between related individuals.

Both inbreeding and genetic drift often lead to high levels of homozygosity, and this is thought to reduce the viability of a population, because of reduced survival and reproduction (Nei $e t$ al. 1975).

Additionally, isolation is also believed to affect the social structure and behaviour of species. For instance cooperative breeding may occur, where offspring of previous years help their parents raise their siblings from this year (Emlen 1996; Stacey \& König 1990). Even co-breeding may occur, where for instance daughters mate with their fathers and have eggs in a shared nest with their mother (Emlen 1996). Because of this behaviour, the level of inbreeding can be very high, and the level of heterozygosity is likely to decrease even faster.

This paper will address the importance of genetic variation for the viability of small avian island- and continental populations and the use of genetic data for conservation planning. We will do this by discussing the results of two studies on isolated or semi-isolated bird species, the Seychelles Warbler Acrocephalus seychellensis and the African Marsh Warbler Acrocephalus baeticatus.

\section{THE SEYCHELLES WARBLER}

A species that is characterised by its population isolation and the occurrence of both cooperative breeding and co-breeding, is the Seychelles Warbler (Komdeur 1992, 1994, 1997). This species is being intensively studied by Komdeur. Between 1959 and 1968 the world population of Seychelles Warblers was threatened by extinction. The entire population consisted of only 26-29 individuals, confined to Cousin Island ( $26 \mathrm{ha}$ ) in the northern Seychelles (Figure 1). Through conservation actions and habitat restoration by BirdLife International, the island population increased gradually and reached a carrying capacity at approximately 320 birds in 1982 . Given the vulnerability of one small island, additional warbler populations were established; 29 birds were successfully translocated from Cousin Island to Aride Island (68 ha) in 1988, and another 29 birds from Cousin Island to Cousine Island (29 ha) in 1990. Because of its passage through the long and narrow population bottleneck, the Seychelles Warbler population is highly inbred and has undergone considerable genetic erosion (Komdeur \& Kappe 1996). This is congruent with the fact that no inbreeding avoidance mechanisms are known to exist in the Seychelles Warbler (Komdeur 1992, 1994, 1996; Komdeur \& Kappe 1996).

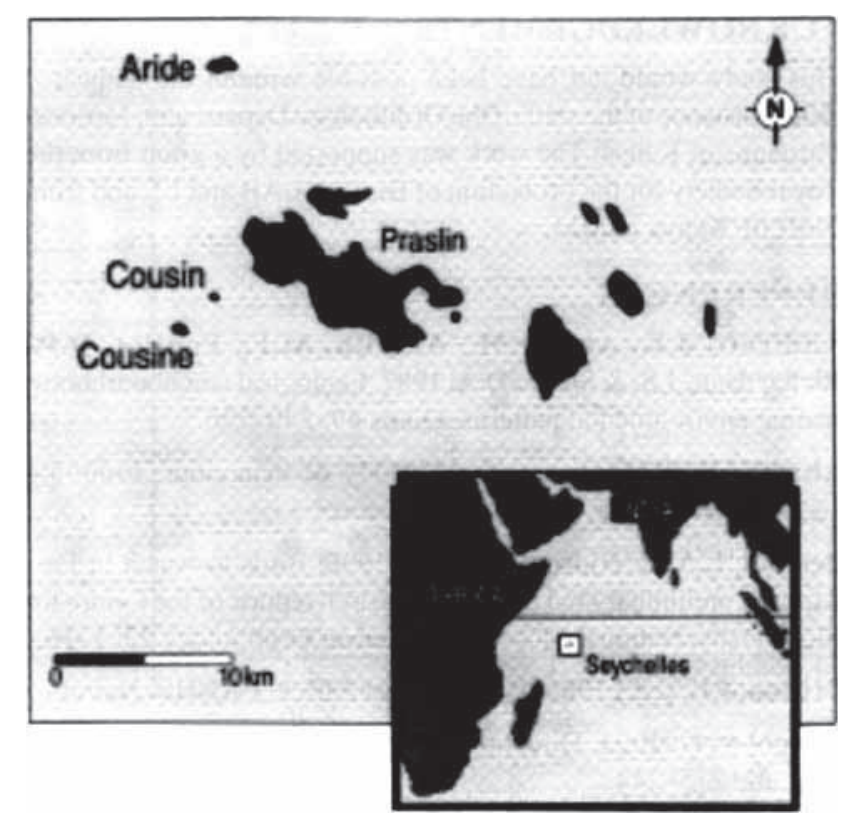

Figure 1. Map showing the position of the Seychelles Islands with populations of Seychelles Warblers: Cousin, Aride and Cousine. 


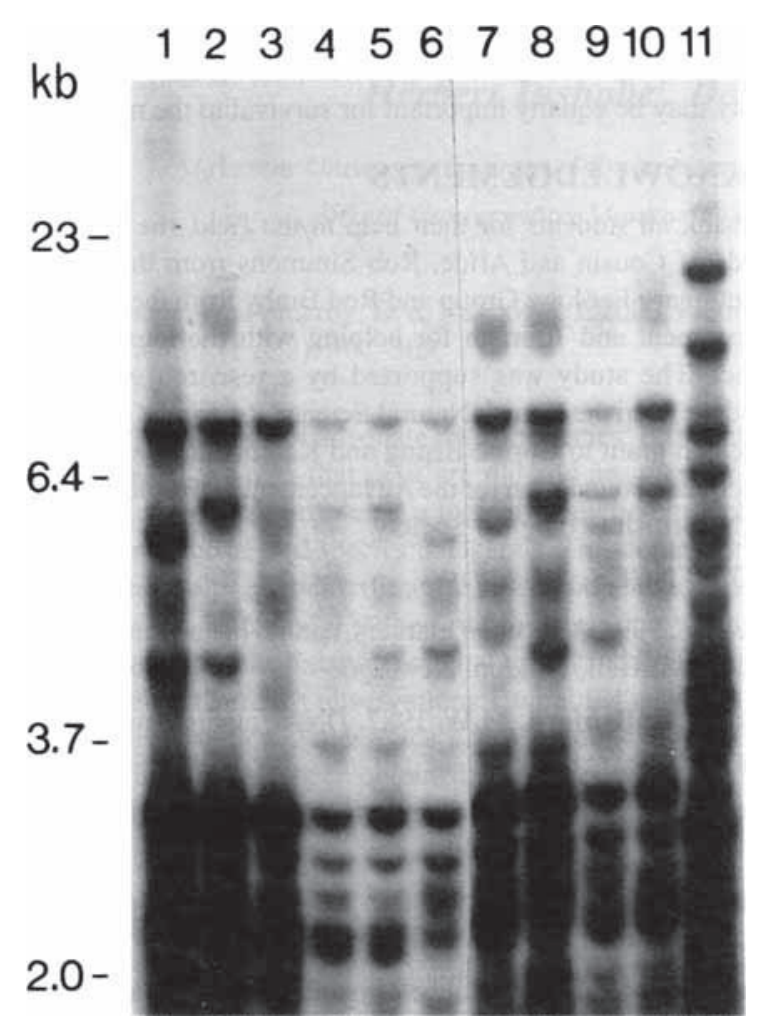

Figure 2. Example of a fingerprint of Seychelles warblers on Cousin and Aride. (From Komdeur \& Kappe 1996).

Figure 2 shows an example of the DNA analysis. Each band represents a certain allele of the warbler genome. The same alleles occur in many individuals, which indicates that their genomes are almost identical and there is little genetic variation. One can calculate the mean band sharing between individuals to obtain an index of their similarity. A mean band sharing of 0.0 indicates that all individuals are completely different, whereas a band sharing of 1.0 indicates that all individuals are identical. The mean band sharing (assessed with Multi Locus DNA Fingerprinting) between warblers was $0.50 \pm 0.01$, which is much higher than recorded for outbred natural bird populations $(0.15-0.20$; Burke \& Bruford 1987; Meng, Carter \& Parkin 1990).
In addition, levels of heterozygosity had dropped by $33 \%$ due to the population bottleneck (Komdeur \& Kappe 1996). It is generally assumed that a low level of heterozygosity coheres with low fitness (Falconer 1981). However, the warblers did not seem to suffer any negative effects on fitness parameters. The additional bottleneck of experimental translocation of 29 inbred Seychelles Warblers to Aride Island had no observed negative effect on fitness. On the contrary, the fecundity and survival of translocated birds on Aride were significantly higher than those of the ancestral Cousin population (Table 1). Warblers on Aride attempted three times more nests per year, doubled clutch-size, and produced 13 times more yearlings per year as compared with warblers on Cousin. This increase in fitness can be explained by the higher territory quality on Aride, measured as mean number of insects present in a warbler territory (Table 1). Because the insectivorous Seychelles Warblers breed and feed in the same territory, territory quality is dependent on insect availability. Eight years after the translocation, the Aride population had grown to over 1000 birds and the level of heterozygosity had remained the same (Komdeur \& Kappe 1996).

\section{IMPLICATIONS}

Although at present the Seychelles Warbler is clearly not negatively affected by the apparent genetic erosion, we cannot conclude that for any inbred island population no management is needed. The translocations occurred to islands with identical indigenous vegetation and climate to those to which the Cousin warblers are used. It is unknown whether the birds are able to adapt to islands comprising introduced vegetation or new parasites. The lack of genetic variation may limit a population's ability to respond to changes in environmental conditions (Avise 1994). In addition, these results cannot be translated to other small populations of different species, because each species has its own species characteristics and history. Because island species are very likely to have survived previous long, narrow bottlenecks and seem to be capable of adaptation to inbreeding, we hypothesise that the effects of 'genetic erosion' on fitness may be less disastrous for island as compared to continental species.

\section{THE AFRICAN MARSH WARBLER}

A parallel study was conducted on a closely related species, the continental African Marsh Warbler, by Blaakmeer and Eising in Namibia in 1995 and 1996. This resident species occurs at the same

Table 1. Comparison of mean annual adult survival, mean breeding performance, mean monthly territory quality of Seychelles Warbler pairs on Cousin lsland and of pairs, comprising Cousin birds, on Aride Island after translocation. Statistical significance of comparisons determined by Chi-squared contingency analysis (percentage data) or two-tailed t-test.

\begin{tabular}{|c|c|c|c|c|}
\hline & & Cousin & Aride & $\mathbf{P}$ \\
\hline Number of observed territories & & 49 & 11 & \\
\hline Annual adult survival & & $81.9 \%(249)$ & $100 \%(65)$ & $<0.025$ \\
\hline \multirow[t]{2}{*}{ Nest-building attempts per Territory } & & $1.8 \pm 1.0$ & $5.5 \pm 1.5$ & $<0.001$ \\
\hline & Total & 177 & 120 & \\
\hline Nests with clutches (\%) & & 64.2 & 88.5 & $<0.005$ \\
\hline \multirow[t]{2}{*}{ Number of nests with clutches per Territory } & & $1.1 \pm 0.7$ & $4.9 \pm 0.9$ & $<0.001$ \\
\hline & Total & 109 & 108 & \\
\hline Mean clutch size & & $1.0 \pm 0.0(55)$ & $1.9 \pm 0.5(40)$ & $<0.005$ \\
\hline Clutches hatched (\%) & & 62.4 & 71.3 & NS $(>0.05)$ \\
\hline \multirow[t]{2}{*}{ Number of nests with pulli per Territory } & & $0.7 \pm 0.8$ & $3.5 \pm 1.1$ & $<0.001$ \\
\hline & Total & 68 & 77 & \\
\hline Nestlings fledged & & 91.2 & 75.3 & NS $(>0.05)$ \\
\hline \multirow[t]{2}{*}{ Number of nests producing fledglings per Territory } & & $0.6 \pm 0.7$ & $2.6 \pm 0.8$ & $<0.001$ \\
\hline & Total & 62 & 58 & \\
\hline Fledglings reaching 1 year of age $(\%)$ & & 27.4 & 100.0 & $<0.001$ \\
\hline \multirow[t]{2}{*}{ Number of yearlings produced per Territory } & & $0.2 \pm 0.2$ & $2.6 \pm 0.8$ & $<0.001$ \\
\hline & Total & 17 & 58 & \\
\hline Mean territory quality & & $16 \pm 10(49)$ & $314 \pm 31(11)$ & $<0.001$ \\
\hline
\end{tabular}




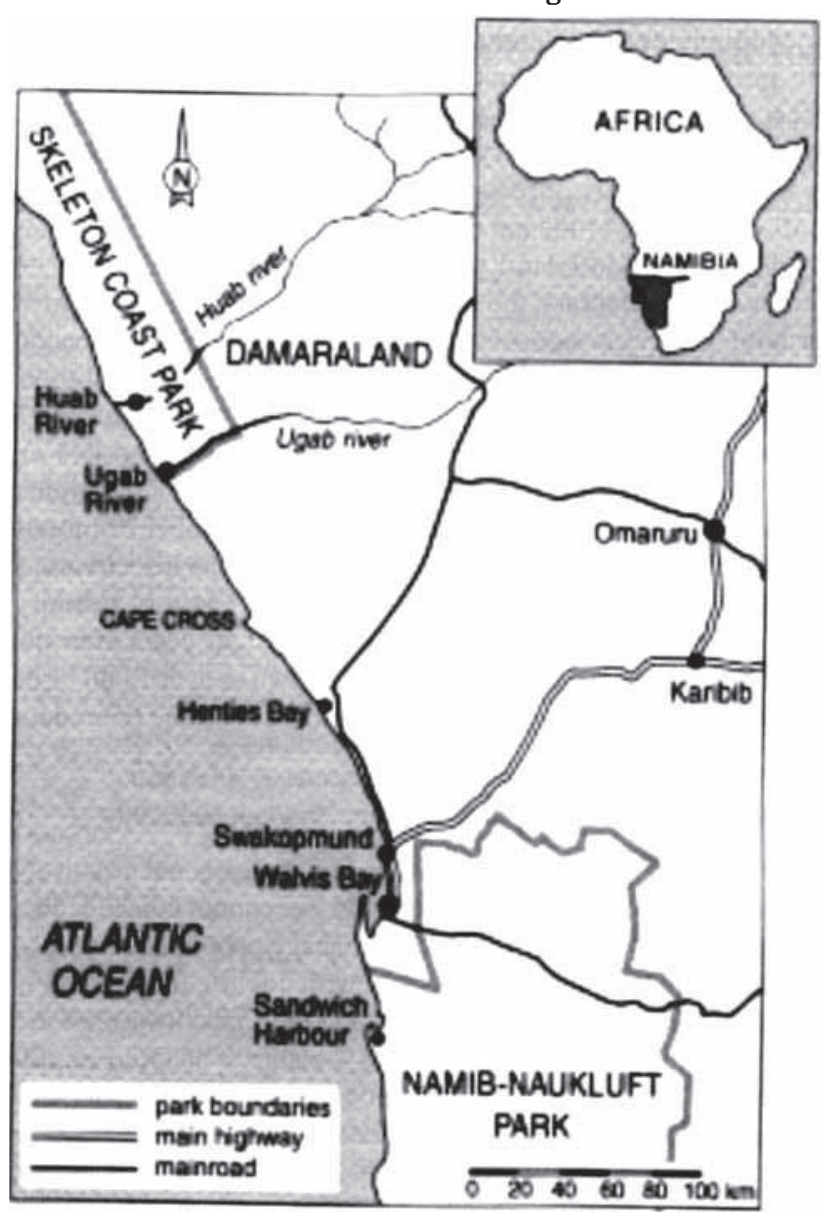

Figure 3. The reedpatches along the Namibian coast where the African Marsh Warblers were studied.

latitude as the Seychelles Warbler, in isolated reedbeds along the Namibian coast. These reed-patches are separated by up to 600 kilometres of harsh, dry desert (Figure 3). It was expected that the African Marsh Warbler would reveal a higher level of genetic variability because observations in 1996 indicate that migration on a small scale is still possible, habitats are presumed to be less saturated, and there has been no severe bottleneck which could have caused a drastic loss of genetic variability. However, cooperative breeding and maybe also cobreeding does occur in the African Marsh Warbler. (Monitoring food provision rates to nestlings at 30 nests in 1996, showed that 7 nests (23.3\%) had helpers). Therefore it is expected that the populations are inbred to some extent. Field data from 1996 suggest that African Marsh Warblers do migrate between patches that are no more than 50 kilometres apart, but most remain in their natal area and therefore, it is expected that the percentage of mean bandsharing will be higher than in outbred populations. This has not yet been tested.

\section{DISCUSSION}

Even if both warbler species appear to be able to cope with medium to high inbreeding frequencies and low heterozygosity, the longterm prospects are supposedly reduced by lack of genetic adaptive potential. It is intended to perform another series of translocation experiments in 1997 to see to what extent these warblers are still capable of adapting to different environments. The results of this study may be used as an indication for what might happen to other isolated species if their numbers are low. and/or their genetic variation is poor. Conservationists should be aware of this genetic threat to small populations when they make plans to protect declining species. On the other hand, some species may not yet be threatened by reduced numbers, but by losing genetic variation. Not only is a species' number important, but the species' (genetic) quality may be equally important for survival to the next decade.

\section{ACKNOWLEDGEMENTS}

We thank all students for their help in the field, the staff on the islands of Cousin and Aride, Rob Simmons from the Namibian Evolutionary Ecology Group and Rod Braby from the Ministry of Environment and Tourism for helping with the logistics of the project. The study was supported by a research grant to Jan Komdeur from the Danish Natural Science Research Councel, and a research grant to Corine Eising and Karen Blaakmeer from the Netherlands Foundation for the Advancement of Tropical Research and the British Ecological Society.

\section{REFERENCES}

Avise, J.C. 1994. Molecular markers, natural history and evolution. Chapman \& Hall, London. New York.

Burke, T. \& Bruford, M.W. 1987. DNA fingerprinting in birds. Nature 327: 149-152.

Emlen, S.T. 1996. Living with relatives: lessons from avian family systems. Ibis 138(1):87-100.

Falconer, D.S. 1981. Introduction to quantitative genetics. 2nd edition, Longman, London and New York.

Komdeur, J. 1992. Importance of habitat saturation and territory quality for evolution of cooperative breeding in the Seychelles warbler. Nature 358: 493-495.

Komdeur, J. 1994. Conserving the Seychelles warbler Acrocephalus seychellensis by translocation from Cousin Island to the Islands of Aride and Cousine. Biol. Conservation 67: 143-152.

Komdeur, J. 1996. Seasonal timing of reproduction in a tropical bird, the Seychelles Warbler: a field experiment using translocation. Journal of Biological Rhythms (in press).

Komdeur, J., Daan, S., Tinbergen, J. \& Mateman, C. 1997. Extreme adaptive modification in sex ratio of the Seychelles warbler's eggs. Nature 385: 522-525.

Komdeur, J. \& Deerenberg, C. 1996. The importance of social behaviour studies for conservation. Chapter 11 In: Clemmons, J.R \& Bucholz, R. (eds.). Behavioral approaches to conservation in the wild. Cambridge University Press, Cambridge.

Komdeur, J. \& Kappe,A. 1996. Influence of population bottlenecks on genetic variation and demography in isolated Seychelles Warbler populations; a field experiment. Proceedings KNAW Colloquium 'Natural selection in wild populations'. Royal Netherlands Academy of Arts and Sciences, Elsevier Science Publishers.

Meng, A., Carter, R.E. \& Parkin, D.T. 1990. The variability of DNA fingerprints in three species of swans. Heredity 64: 73-80.

Nei, M., Maruyama, T. \& Chakraborty, R. 1975. The bottleneck effect and genetic variability in populations. Evolution 29(1): 1-10.

Soulé, M.E. 1987 (ed.): Viable populations for conservation. Cambridge University Press, Cambridge. 